\title{
Steroid synthesis in ovarian homogenates from immature mice treated with diethylstilboestrol in neonatal life*
}

\author{
A. Halling and J.-G. Forsberg \\ Department of Anatomy, University of Lund, Biskopsgatan 7, S-223 62 Lund, Sweden
}

\begin{abstract}
Summary. Female mice of the NMRI strain were treated with the synthetic oestrogen diethylstilboestrol (DES) for the first 5 days after birth. Pools of ovaries were removed from groups of 6-, 12-, 21-, 28- and 56-day-old females. An homogenate of an ovarian pool was incubated for $1 \mathrm{~h}$ in the presence of $\left[{ }^{3} \mathrm{H}\right]$ pregnenolone. Synthesized steroids were extracted and separated in a two-dimensional thin-layer chromatography system. Homogeneity of tentative steroids was verified with recrystallization to constant specific activity. Synthesis of $\left[{ }^{3} \mathrm{H}\right]$ progesterone and $\left[{ }^{3} \mathrm{H}\right]$ testosterone was demonstrated at 6 days, $\left[{ }^{3} \mathrm{H}\right]$ androstenedione at 12 days, $\left[{ }^{3} \mathrm{H}\right] 17 \alpha$-hydroxyprogesterone at 21 days, and $\left[{ }^{3} \mathrm{H}\right]$ oestradiol- $17 \beta$ at 28 days. Up to 28 days ( 21 days for progesterone), the synthetic activity was lower in homogenates of DES-exposed ovaries than in control homogenates. After 28 days, values for recovered $\left[{ }^{3} \mathrm{H}\right]$ progesterone, $\left[{ }^{3} \mathrm{H}\right]$ androstenedione and $\left[{ }^{3} \mathrm{H}\right]$ oestradiol- $17 \beta$ were higher in DES homogenates than in control homogenates while the reverse was true for $\left[{ }^{3} \mathrm{H}\right] 17 \alpha$-hydroxyprogesterone and $\left[{ }^{3} \mathrm{H}\right]$ testosterone. The results are compatible with an early and direct DES inhibitory effect on ovarian steroidogenesis and, later in immature life, a DES-induced disruption of the normal FSH-LH stimulation of ovarian development.
\end{abstract}

Keywords: steroids; synthesis; ovary; mouse; diethylstilboestrol

\section{Introduction}

Post-pubertal female mice, treated with oestrogens for the first few days after birth, have permanent vaginal cornification and are sterile. The ovaries are characterized by lacking corpora lutea but having follicles in different stages of development, many of the multi-oocyte type, and hypertrophyhyperplasia of the interstitial tissue (Takasugi \& Bern, 1964; Forsberg, 1969; Forsberg et al., 1985; Iguchi, 1985; Iguchi et al., 1986). Similar changes also occur in the offspring from oestrogen-treated pregnant females (Haney et al., 1984). The ovarian changes are generally considered to be secondary to an oestrogen-induced disturbance in hypothalamic-pituitary control, resulting in no LH peaks and no ovulation (Plapinger \& McEwen, 1978). When steroid synthesis in ovarian homogenates from 8-week-old control female mice was compared to that in similar homogenates from neonatally diethylstilboestrol (DES)-treated females, using $\left[{ }^{3} \mathrm{H}\right]$ pregnenolone as precursor, the pattern of steroids formed was different. Homogenates from neonatally DES-exposed ovaries were characterized by, compared with controls, an increased synthesis of progesterone and androstenedione while the synthesis of $17 \alpha$-hydroxyprogesterone and testosterone was reduced (Tenenbaum \& Forsberg, 1985). A difference in plasma concentration of testosterone, but not progesterone, has been described (Tenenbaum et al., 1985; Halling \& Forsberg, 1989).

The aim of the present study was to determine when a difference in steroidogenic pattern between ovarian homogenates from control females and from similarly aged but neonatally DES-treated females can first be demonstrated.

${ }^{*}$ Reprint requests to Dr J.-G. Forsberg. 


\section{Materials and Methods}

Animals. The animals used belong to a closed colony of the NMRI strain, originally obtained from Charles River Wiga, Sulzfeld, FRG. They were kept in a controlled environment (temperature and humidity) and fed a standard pellet diet and tap water ad libitum. Serum was regularly checked for absence of antibodies to mouse hepatitis virus.

Females were allowed to give birth to their litter in separate cages. Within $24 \mathrm{~h}$ after birth, the newborn young were sexed and every mother was allotted a pooled litter culled to 8 females. These neonatal females were treated with $5 \mu \mathrm{g}$ diethylstilboestrol (DES; Sigma Chemical Co., St Louis, MO, USA) in $0.05 \mathrm{ml}$ vehicle (physiological buffered saline/dimethyl sulphoxide: 19/1 v/v; 2 drops of Tween 80 per $20 \mathrm{ml}$ solution; dimethyl suphoxide from E. Merck, AG, Darmstadt, FRG) on each of the first 5 days after birth, starting within $24 \mathrm{~h}$ after birth and then every $24 \mathrm{~h}$. The vehicle with DES was injected subcutaneously. Controls were injected with vehicle only.

The females were killed by cervical dislocation on Days 6, 12, 21, 28 and 56 after birth and the ovaries were dissected out under a dissecting microscope. To get an amount of ovarian tissue corresponding to that of both ovaries from the 56-day-old females, ovaries from up to 30 females had to be pooled from 6-day-old females. Lower numbers of females were used at each experiment from the 12-, 21 - and 28-day stages but it was still necessary to pool ovaries from several females.

Homogenization and incubation of ovarian tissue. After removal from the females, the ovaries were put into ice-cold Medium 199 (Statens Bakteriologiska Laboratorium, Stockholm, Sweden). When the pool of ovaries was considered of suitable size for the age stage, the ovaries were weighed after the medium had been carefully wiped away. Between 28 and $35 \mathrm{mg}$ ovarian tissue were used in each pool. After weighing, the pooled ovaries were transferred to $2 \mathrm{ml}$ icecold Medium 199 and homogenized for $15 \mathrm{sec}$ while cooling on ice (Polytron homogenizer, type PT, at setting 10).

Each homogenate was divided into two equal portions and $1 \mathrm{ml}$ Medium 199 and 440000 d.p.m. [7- ${ }^{3} \mathrm{H}(\mathrm{N})$ ] pregnenolone (10.3 pmol; sp. act. $19 \cdot 3 \mathrm{Ci} / \mathrm{mmol}$; purity tested on thin-layer chromatography at use was $>90 \%$; New England Nuclear, Boston, MA, USA) in $20 \mu$ physiological buffered saline (PBS; $\mathrm{pH} 7 \cdot 4)$ were added to each sample. This was further supplemented with $200 \mu \mathrm{l}$ glucose 6 -phosphate $(50 \mu \mathrm{M}$; monosodium salt; Sigma Chemical Co.), $200 \mu \mathrm{l} \beta$-nicotinamide adenine dinucleotide phosphate $(50 \mu \mathrm{M}$; free acid; NADP, Sigma Chemical Co. $)$ and $100 \mu 1$ glucose 6-phosphate dehydrogenase ( 5 units; type IX, from bakers yeast; Sigma Chemical Co.). The homogenates were incubated for $1 \mathrm{~h}$ at $37^{\circ} \mathrm{C}$ in an atmosphere of $95 \%$ air and $5 \% \mathrm{CO}_{2}$.

Incubation was stopped with $3 \mathrm{ml}$ ethyl acetate (E. Merck AG). After shaking at room temperature overnight, the tubes were centrifuged at $750 \mathrm{~g}_{\mathrm{av}}$ for $5 \mathrm{~min}$ and the ethyl acetate fractions were transferred to a new set of tubes. The water phase was reshaken twice for $1 \mathrm{~h}$, each time with $3 \mathrm{ml}$ ethyl acetate. The resulting ethyl acetate fraction of $9 \mathrm{ml}$ was evaporated and stored at $60^{\circ} \mathrm{C}$ over night.

Thin-layer chromatography. The extracted steroids from the homogenate were redissolved in $100 \mu l$ ethanol and put on Silica gel plates 60F 254 (precoated, $20 \times 20 \mathrm{~cm}$, thickness $0.25 \mathrm{~mm}$; E. Merck AG) together with reference steroids (all from Sigma Chemical Co.; dissolved in ethanol at a concentration of $5 \mathrm{mg} / \mathrm{ml}$ ).

The following non-radioactive reference steroids were used (all from Sigma Chemical Co.): pregnenolone $\left(\Delta^{5}\right.$ pregnen-3 $\beta$-ol-20-one); progesterone ( $\Delta^{4}$-pregnen-3,20-dione); 17 $\alpha$-hydroxyprogesterone $\left(\Delta^{4}\right.$-pregnen-17 $\alpha$-ol-3,20dione); androstenedione ( $\Delta^{4}$-androstene-3,17-dione); testosterone ( $\Delta^{4}$-androsten-7 $\beta$-ol-3-one); oestradiol-17 $\beta$ $\left(\Delta^{1,3.5,(10)}\right.$-oestratrien-3-17 $\beta$-diol).

The following steps in the two-dimensional thin layer chromatography (t.l.c.) method were as described by Tenenbaum \& Forsberg (1985). The validity of the incubation procedure and t.l.c. method has been verified in kinetic studies (Tenenbaum \& Forsberg, 1985).

Counting of radioactivity (d.p.m.) took place in a LKB 1214 Rackbeta scintillation counter. The scintillation fluid was Instagel (Packard Instrument Inc., Downers Grove, IL, USA). Counting efficiency was 53-54\%.

In special experiments, known amounts of ${ }^{3} \mathrm{H}$-labelled reference steroids (New England Nuclear) were added to homogenates (not supplemented with $\left[{ }^{3} \mathrm{H}\right]$ pegnenolone) before addition of ethyl acetate. The amount of radioactivity extracted from corresponding areas of the plates indicated the percentage of recovery and the loss during the technical procedure. The recovery was $>94 \%$ and did not vary significantly among different steroids. The identity of the steroids in different areas on the plates (control and DES samples) was confirmed by recrystallization to constant specific activity, using ${ }^{14} \mathrm{C}$-labelled marker steroid, and unlabelled carrier steroid as earlier described (Tenenbaum $\&$ Forsberg, 1985). The quotients between ${ }^{3} \mathrm{H}$ - and ${ }^{14} \mathrm{C}$-steroids in the final crystals (after 5 recrystallization steps) were related to the same quotient in the plate eluate and the resulting percentage was used as a measure of homogeneity of ${ }^{3} \mathrm{H}$-steroid in the plate area. For $\left[{ }^{3} \mathrm{H}\right]$ progesterone the percentage was $>96 \%$, for $\left[{ }^{3} \mathrm{H}\right]$ oestradiol-17 $>>95 \%$, for $\left[{ }^{3} \mathrm{H}\right]$ testosterone $100 \%$, for $\left[{ }^{3} \mathrm{H}\right]$ androstenedione $100 \%$, and for $\left[{ }^{3} \mathrm{H}\right] 17 \alpha$-hydroxyprogesterone $44 \%$.

The d.p.m. values obtained from the scintillator were corrected for differences in efficiency of the scintillation fluid to extract different steroids from the plate material and, for $\left[{ }^{3} \mathrm{H}\right] 17 \alpha$-hydroxyprogesterone, also for heterogeneity as shown by the recrystallization experiments.

Statistics. All statistical estimations were based on logarithmically ( $\left.{ }^{10} \mathrm{log}\right)$ transformed data. At each age studied for a particular steroid, a $t$ value (Student's $t$ test) was calculated and a $\chi^{2}$ value was obtained from the sum of the squared $t$ values. The $\chi^{2}$ represents the probability for a difference in synthesis of a specific steroid between control and DES homogenates at all ages; the individual $t$ value identifies the probability for a possible difference at a specific age. Significance levels: $0.05>P>0.01$ probably significant; $0.01>P>0.001$ significant; $P<0.001$ highly significant. 


\section{Results}

An overview of the results is given in Fig. 1 . For $\left[{ }^{3} \mathrm{H}\right]$ progesterone there was a highly significant over-all difference between the results from homogenates of control ovaries (control homogenates) and those from homogenates of DES-exposed ovaries (DES homogenates). Low amounts of $\left[{ }^{3} \mathrm{H}\right]$ progesterone were recovered from ovarian homogenates from 6-day-old females (Fig. 1a). There was only a slight but significant difference between the results from homogenates of control ovaries (control homogenates) and those from homogenates of DES-exposed ovaries (DES homogenates); all the DES results were below those of the controls. This difference was accentuated at 12 days when the $\left[{ }^{3} \mathrm{H}\right]$ progesterone formation had increased in control homogenates while the values from DES homogenates remained at a low level. During the period 12-28 days, synthesis was at a constant level in control homogenates but increased after Day 28 to reach a significantly higher level at Day 56 than at any of the 3 prior age stages studied. At 21 and 28 days, synthesis was similar in control and DES homogenates but at 56 days it was different and probably significantly higher in DES homogenates than in controls.

Only trace amounts of $\left[{ }^{3} \mathrm{H}\right] 17 \alpha$-hydroxyprogesterone were recovered at 6 days and the values were similar in control and DES homogenates (Fig. 1b). A significant synthesis was not seen until Day 21 in control homogenates and at Day 28 in DES homogenates. During the interval 28-56 days, the formation of this steroid increased abruptly in control homogenates but only slightly in DES homogenates. At 21, 28 and 56 days the amount of $\left[{ }^{3} \mathrm{H}\right] 17 \alpha$-hydroxyprogesterone recovered from control homogenates was significantly higher than that from DES homogenates.

For $\left[{ }^{3} \mathrm{H}\right]$ androstenedione there was a quite different pattern of radioactivity recovered from control and DES homogenates (Fig. 1c). In controls, synthesis was first seen at 12 days and increased significantly during the interval between Day 12 and Day 21 . A variance analysis of the values from the stages at 21,28 and 56 days indicated a probably significant difference which could be ascribed to lower values at Day 56 compared with Day 28. Synthesis in DES homogenates increased steeply from low values at 21 days to about a 4-fold higher level than controls at 56 days.

The $\left[{ }^{3} \mathrm{H}\right]$ testosterone synthesis in the whole material of DES homogenates was highly significant different from that in control homogenates. The level was lower in DES homogenates than in controls (Fig. 1d). Turning to the separate age stages, the difference between controls and DES homogenates was not significant at 6 days, probably significant at 12 and 21 days, significant at 28 days and highly significant at 56 days. At the later age, the radioactivity representing $\left[{ }^{3} \mathrm{H}\right]$ testosterone was about twice as high in control homogenates as in DES homogenates.

Only trace amounts of $\left[{ }^{3} \mathrm{H}\right]$ oestradiol- $17 \beta$ were recovered from control homogenates at all ages studied (Fig. le). At 28 days, there was a tendency for more $\left[{ }^{3} \mathrm{H}\right]$ oestradiol being formed in DES homogenates than in control homogenates. At 56 days the mean $\left[{ }^{3} \mathrm{H}\right]$ oestradiol synthesis was about 11 -fold higher in DES homogenates than in controls.

\section{Discussion}

The present study of steroid synthesis in homogenates of pooled ovaries from 56-day-old control or neonatally DES-treated females verified and extended earlier reported results (Tenenbaum \& Forsberg, 1985): the synthesis of progesterone, androstenedione and oestradiol reached higher levels in DES homogenates than in control homogenates while the reverse was true for $17 \alpha$ hydroxyprogesterone and testosterone. At 56 days, control females are cycling but fluctuations in ovarian steroidogenic activity, related to different phases of the oestrous cycle, are not so pronounced as to influence the basic difference between control and DES ovaries (Tenenbaum \& Forsberg, 1985). A daily dose of $5 \mu \mathrm{g}$ DES in the neonatal period was chosen because it has earlier shown to have a pronounced effect on ovarian steroidogenesis in adult females (Tenenbaum \& Forsberg, 1985). 

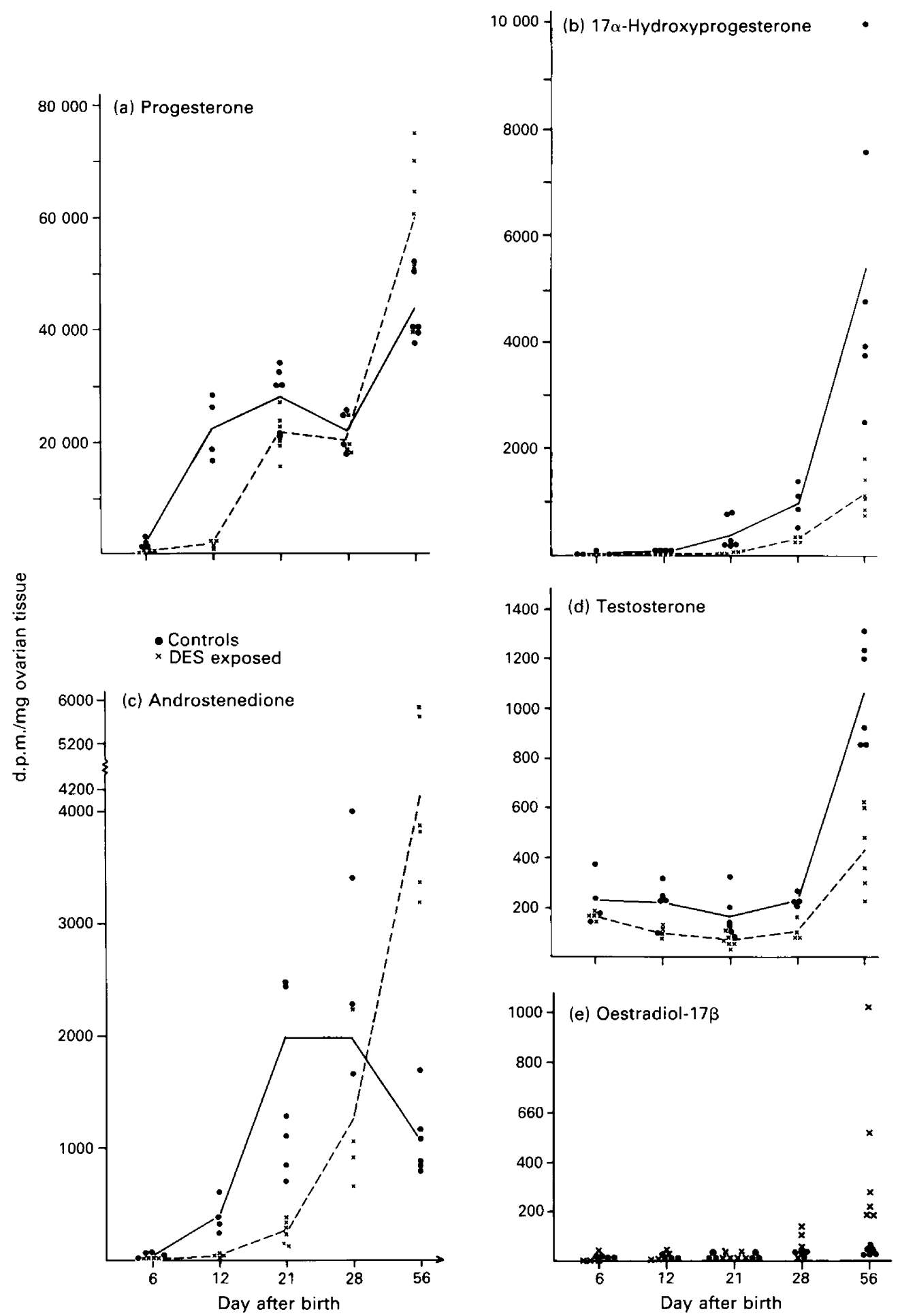

Fig. 1. The pattern of steroid synthesis in homogenates of ovaries from neonatally DES-treated females $(x)$ or control females $(\bullet)$, at different ages. The d.p.m. values given were obtained after correction as described in 'Materials and Methods'. Each point on the figures represents the result from one experiment, based on pooled ovaries. 
Ovaries from 7- to 20-day-old mice secrete progesterone, androstenedione and testosterone into the culture medium (Fortune \& Eppig, 1979). Using $\left[{ }^{3} \mathrm{H}\right]$ pregnenolone as substrate, an overall increase in steroidogenic activity was described from mouse ovaries between 7 and 38 days after birth, progesterone being the major metabolite and androstenedione the major androgen (Mannan \& O'Shaughnessy, 1988). Lower amounts of $17 \alpha$-hydroxyprogesterone and testosterone but only traces of oestrogens were formed. The pattern of progesterone, androstenedione, and oestradiol synthesis from pregnenolone in control homogenates in the present study is similar to that described for normal mouse ovaries by Mannan \& O'Shaughnessy (1988). However, the peak of synthetic activity of $17 \alpha$-hydroxyprogesterone and testosterone found by Mannan \& O'Shaughnessy (1988) on Day 38 could not be verified in the present study because it did not include data from that stage.

The adult difference in steroid synthetic pattern between homogenates of DES ovaries and control ovaries emerged after the 28 -day stage; before that, the pattern was similar but the synthetic activity was lower in DES homogenates. Events after the 28-day stage therefore seem to be of special importance for this pattern divergence in steroidogenic activity between homogenates of control and DES ovaries.

In adult, mutant hypogonadal mice, with lack of $\mathrm{GnRH}$ and very low serum concentrations of gonadotrophins, the pattern of steroid metabolism was similar to that of 7-day-old normal mice although 17-ketosteroid reductase and aromatase activity were low compared to normal animals of any age (Mannan \& O'Shaughnessy, 1988). The difference in steroid metabolism between adult mutant mice and adult DES-treated mice therefore argues for the latter not being 'hypogonadal' because of failure of gonadotrophin secretion. Nor is the ovarian steroidogenesis in these mice similar to that in rats after long-term hypophysectomy (Kim \& Greenwald, 1984).

A primary effect of the neonatal oestrogen treatment is considered to be in the hypothalamicpituitary control system (Goomer et al., 1977; Gorski et al., 1977; Plapinger \& McEwen, 1978). In mice, gonadotrophins are present in the circulation from birth onward (Dullaart et al., 1975) and the ovary responds to gonadotrophins (Hardy et al., 1974; Purandare et al., 1976; Lintern-Moore, 1977; Terada et al., 1984). Depending on the strain, peaks of LH and FSH activity occur in mice between Days 8 and 15 after birth (Stiff et al., 1974; Dullaart et al., 1975; Raghavan et al., 1977). A high plasma FSH concentration has been described during the first 10 days of mouse life, falling to adult levels over the next 20 days (Halpin et al., 1986). An early DES-induced disturbance in the age-dependent relationship between FSH and LH could thus affect ovarian function not only in adult but also in immature life as described in the present study. The generally reduced steroidogenic activity in DES homogenates in young immature mice may, however, also be due to a delayed and direct effect of the drug on the activity of steroidogenic enzymes involved in pregnenolone metabolism (Spona, 1983).

Except for the occurrence of numerous multi-oocyte follicles in DES ovaries and a slight developmental retardation with respect to appearance of bi-layered follicles and antrum formation, DES ovaries and control ovaries were morphologically similar in females younger than 35 days (Forsberg et al., 1985). At 8 weeks, DES ovaries had no corpora lutea but hyperplasia-hypertrophy of the interstitial cells which thus could be related to the deviating pattern of steroidogenesis.

This investigation was supported by grants from the Swedish Medical Research Council (grant no. B88-12X-7881-02B).

\section{References}

Dullaart, J., Kent, J. \& Ryle, M. (1975) Serum gonadotrophin concentrations in infant female mice. $J$. Reprod. Fert. 43, 189-192.

Forsberg, J.-G. (1969) The development of atypical epithelium in the mouse uterine cervix and vaginal fornix after neonatal oestradiol treatment. Br.J.exp. Pathol. 50, 187-195.

Forsberg, J.-G., Tenenbaum, A., Rydberg, C. \& Sernvi, C. (1985) Ovarian structure and function in neonatally estrogen treated female mice. In Estrogens in the 
Environment, vol.II,pp.327-346. Ed.J.A. McLachlan. Elsevier Science Publishing Co. Inc., New York.

Fortune, J.E. \& Eppig, J.J. (1979) Effects of gonadotropins on steroid secretion by infantile and juvenile mouse ovaries in vitro. Endocrinology 105, 760-768.

Goomer, N., Saxena, R.N. \& Sheth, A.R. (1977) Effect of neonatal testosterone and oestradiol treatment on the development of the hypothalamo-hypophysial axis in the female rat. J. Reprod. Fert. 50, 239-243.

Gorski, R.A., Harlan, R.E. \& Christensen, L.W. (1977) Perinatal hormonal exposure and the development of neuroendocrine regulatory processes. J. Toxicol. Environm. Health 3, 97-121.

Halling, A. \& Forsberg, J.-G. (1989) Plasma testosterone levels and ovarian testosterone content in adult mice treated with diethylstilbestrol neonatally. J. Steroid Biochem. 32, 439-443.

Halpin, D.M.G., Jones, A., Fink, G. \& Charlton, H.M. (1986) Postnatal ovarian follicle development in hypogonadal (hpg) and normal mice and associated changes in the hypothalamic-pituitary axis. J. Reprod. Fert. 77, 287-296.

Haney, A.F., Newbold, R.R. McLachlan, J.A. (1984) Prenatal diethylstilbestrol exposure in the mouse: effects on ovarian histology and steroidogenesis in vitro. Biol. Reprod. 30, 471-478.

Hardy, B., Danon, D., Eshkol, A. \& Lunenfeld, B. (1974) Ultrastructural changes in the ovaries of infant mice deprived of endogenous gonadotrophins and after substitution of FSH. J. Reprod. Fert. 36, 345-352.

Iguchi, T. (1985) Occurrence of polyovular follicles in ovaries of mice treated neonatally with diethylstilbestrol. Proc. Jap. Acad. Series B 61, 288-291.

Iguchi, T., Takasugi, N., Bern, H.A. \& Mills, K.T. (1986) Frequent occurrence of polyovular follicles in ovaries of mice exposed neonatally to diethylstilbestrol. Teratology 34, 29-35.

Kim, I. \& Greenwald, G.S. (1984) Further studies on in vitro steroidogenesis by luteal cells from long-term hypophysectomized rats. Biol. Reprod. 30, 824-832.

Lintern-Moore, S. (1977) Initiation of follicular growth in the infant mouse ovary by exogenous gonadotropins. Biol. Reprod. 17, 635-639.
Mannan, M.A. \& O'Shaughnessy, P.J. (1988) Ovarian steroid metabolism during post-natal development in the normal mouse and in the adult hypogonadal (hpg) mouse. J. Reprod. Fert. 82, 727-734.

Plapinger, L. \& McEwen, B.S. (1978) Gonadal steroidbrain interactions in sexual differentiation. In Biological Determinants of Sexual Behaviour, pp. 153-218. Ed. J. B. Hutchinson. John Wiley, Chichester, New York.

Purandare, T.V., Munshi, S.R. \& Rao, S.S. (1976) Effect of antisera to gonadotropins on follicular development in mice. Biol. Reprod. 15, 311-320.

Raghavan, V., Purandare, T.V., Sheth, A.R. \& Munshi, S.R. (1977) Circulating levels of gonadotrophins in immature mice treated neonatally with antisera to gonadotrophins. J. Reprod. Fert. 49, 401-403.

Spona, J. (1983) Differences in inhibition by various steroids of rat testis and Pseudomonas testosteronii $\Delta^{5}$-3 $\beta$-hydroxysteroid dehydrogenase. Endocr. exp. 17, 107-118.

Stifi, M.E., Bronson, F.H. \& Stetson, M.H. (1974) Plasma gonadotropins in prenatal and prepubertal female mice: disorganization of pubertal cycles in absence of the male. Endocrinology 94, 492-496.

Takasugi, N. \& Bern, H.A. (1964) Tissue changes in mice with persistent vaginal cornification induced by early postnatal treatment with estrogen. J. natn. Cancer Inst. 33, 855-865.

Tenenbaum, A. \& Forsberg, J.-G. (1985) Structural and functional changes in ovaries from adult mice treated with diethylstilboestrol in the neonatal period. $J$. Reprod. Fert. 73, 465-477.

Tenenbaum, A., Sernvi, C. \& Forsberg, J.-G. (1985) Ovarian progesterone synthesis and content and plasma progesterone levels in adult mice treated with diethylstilbestrol neonatally. Biol. Res. in Pregnancy 6, 143-149.

Terada, N., Kuroda, H., Namiki, M., Kitamura, Y. \& Matsumoto, K. (1984) Augmentation of aromatase activity by FSH in ovaries of fetal and neonatal mice in organ culture. J. Steroid Biochem. 20, 741-745.

Received 18 July 1989 